\title{
THE USE OF AN INNOVATION CLASSROOM: A Perspective in the Introduction of ICT in Elementary Schools
}

\author{
José Del Carmen Barrios, Miguel Ángel Rodríguez, Ernesto Sánchez Schultz \\ Conéctate al Conocimiento Project, Clayton, Panamá \\ jdcbarrios@gmail.com, miguel.rodriguez@conectate.edu.pa,,ernesto.sanchez@conectate.edu.pa,
}

Keywords: Collaboration, knowledge, Aula de Innovación, innovation, classroom, concept maps, CmapTools, Panamá

Abstract: In Panama, ICT's (Information and Communication Technologies) are implemented in elementary schools through the Conéctate al Conocimiento project (Tarté, 2006). This project has reached up to more than 700 schools across the country, providing them with the tools to create a national knowledge network. All this effort is towards the promotion on knowledge construction and collaboration in such construction. The aforementioned requires constant practice and feedback if what one pretends to achieve is that the individual can express through the tool without being limited by it, that the tool becomes a springboard to build, express and share his/her knowledge. This paper will show an approach to the introduction of ICT's in schools through a new model called Aula de Innovación (Innovation Classroom). We also show examples that support the validity of the model, it is not a recipe book that can be applied in any context, but a concrete experience that allows us to guide and point out some key issues in school activities regarding the use of ICT's. The objective of this paper is to share an approach in the use ICT as a tool to collaborate in the building, sharing and publishing knowledge.

\section{INTRODUCTION}

The introduction of ICT in education, to be more precise, in educational tasks, has always been a topic for debate. Nowadays, no one rejects the importance that the presence of ITC's has in the integral education of our students, regardless of the educational level; however, the topic takes relevance when we think in which is the best manner to carry out such a task. The traditional instructional models are starting to yield terrain to learning environments that are better self-regulated, in which the spatial and temporal symmetries are starting to be modified by the people and the educational institutions are becoming organizations that learn in community. This last item is not a generality, much less in Latin America, where much of the educational models lack on ICT integration, sometimes for budgetary deficiencies and in other cases because of pedagogical model driven and centered solely on ICT's.

Conéctate al Conocimiento project is introducing progressively ICT's in elementary schools in the Republic of Panama, this is done in an environment which allows the students and teachers to construct, publish and share knowledge, which is Conéctate al Conocimiento main objective, in order to have a future society with individuals that had the opportunity and developed the abilities that allow them to be competitive. It is then, when we see technology performing a role of mean and support for a network of people (students, teachers, community in general), so the ICT's potentiate the capacity to perform meaningful educational transformations. The bet for the incorporation of ICT's has been the model of the Aula de Innovación (AI, its English literal translation is Innovation Classroom) which is the place where all the computational equipment is placed. The physical design of the as well as the functional design were conceived to avoid "techno centrism" and made the AI a place for the construction of knowledge, leaving aside the traditional "computer lab" where the students go to learn about software and computers and where the machine has a leading role. The pedagogical model behind the AI implies the use of computers with the final goal of learning sciences, mathematics, language, etc. and to allow the student to develop the higher thinking abilities during the learning process. In order for the 
aforementioned isn't just already spoken and heard poetry, Conéctate al Conocimiento is trying to abruptly land all the epistemological ideas about ICT's and education, in a model that possesses four important components: a) Equipment, b) Permanent training, support and follow-up c) Empowering the schools by giving them an active role in the process and d) Creating support networks among the peers to make it a self-sustainable process.

Encompassing all of the above, the AI becomes a space that affords that processes such as collaboration, knowledge construction and meaningful learning can take place. This article describes what is an AI? Which pedagogical model it implements? The role of the AI coordinator (CAI) and which are Conéctate al Conocimiento projections to include other models according to the necessity and always looking for educational equity.

\section{WHAT IS AN INNOVATION CLASSROOM?}

An Innovation Classroom AI is physical space designed specifically for knowledge building and meaningful learning. This space is equipped with technological tools that promote communication and knowledge sharing and publishing among the schools. The main objective for an Innovation Classroom is to serve as a platform to a great national school network promoted by the Conéctate al Conocimiento Project (Tarté 2006). This network is propeled by students, teachers, parents and the community in general.

The whole concept of an Innovation Classroom is oriented towards promoting the use of technology as an excellent tool to obtain better results in the learning process. But the role that technology plays is secondary because it is just a tool and not the final goal, which sets us apart from the common technocentered approach. Conéctate al Conocimiento Project is formed with the goal of developing a Panamanian society which is able to take advantage, with equity, of connectivity, and at the same times enhances innovation

The AI concept is being implemented in government elementary schools across all the country. There are around eight hundred AI's built and equiped which are distributed in all the country's provinces and reservations. Each $\mathrm{AI}$ is equiqued by the project with computers, printers, digital cameras, projectors, scanners, a server with a public IP and Internet access. Through the IC the community gain access to the Internet, the schools can network and access services such as e-mail, a meeting space called "Punto de Encuentro" (meeting point), discussion thread, chat service, content publishing and distance learning system. The project provides every service needed in the AI, such as equipment, structural fittingouts, furniture, services and support.

\section{WHAT DOES AN AI HAVE?}

The AI includes tables, chairs and computer equipment. The computer equipment will be organized accordingly to the description in the Diagram No. 1 (See figure 1).

The equipment is assigned to the $\mathrm{AI}$ in accordance to the number of students of the classroom with the most population, divided into two which will yield the number of computers, the computers are assigned one for every two students in order to promote sharing and collaboration, and teamwork. To these computers it is added a printer, a scanner, a server, a digital camera and a projection screen. Besides all this, the AI has Internet access. The server is prepared in the project with the corresponding information for the school; the technician in charge of the installation should verify its configuration.

The computers in the AI are connected to a Local Area Network with Internet access, the LAN could be via structured wire lying or wireless access. The AI counts with one computer which is assigned to the CAI teacher.

The computers that the students, the teachers and the CAI use were originally programmed with a group of software that will allow them to carry out their learning activities. These computers come with the following configuration: Windows XP Profesional Operating System, Microsoft Office, CmapTools (A knowledge modeling kit to build concept maps), Scanner management software, Printer management software.

Recently, the program Spark has been added in the newer installations and maintenance roll-outs due to the necessity of intercommunication and collaboration.

The server that contains the students work: Linux Operating System, CmapServer Program (software for the concept map application), Printer Management Software. 


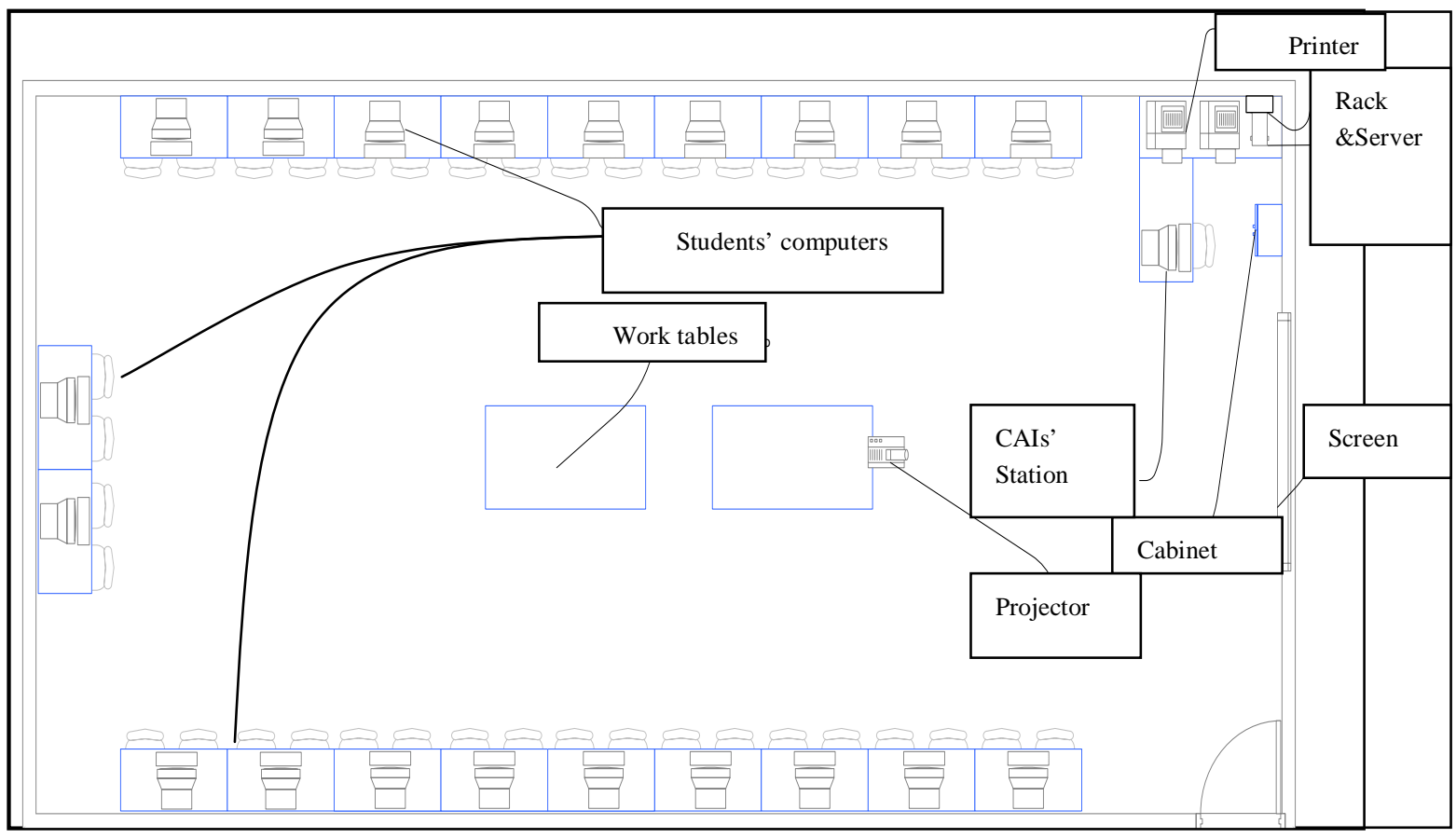

Figure 1: Diagram of the AI

\section{WHAT'S NEW IN THE AI MODEL?}

The AI was thought of as a different conception from the traditional computer lab. The differences between these two approaches include physical and spatial distribution, its purpose and the manner in which the users interact within.

\subsection{How is a traditional computer lab?}

Figure 2(top) shows a spatial distribution for a typical "computer lab" of and educational institution in Panamá. This model presents some limitations such as that the teachers can move in the lines to help students, but, once they are in a row, they are no able to observe the following rows and quickly grasp what the students are doing in order to offer help. The teacher's role consists of "explaining" how the applications and equipment operate so the students start learning about the machine itself and not about the topics covered in the educational curriculum or develop abilities with the help of the computers.
Computers are spatially distributed in exactly the same manner of rows and columns that the chairs in a traditional classroom (Figure 2 bottom). The interaction among the individuals is limited by the presence of the computers that block any exchange of ideas or opinions among the students that are not physically close.

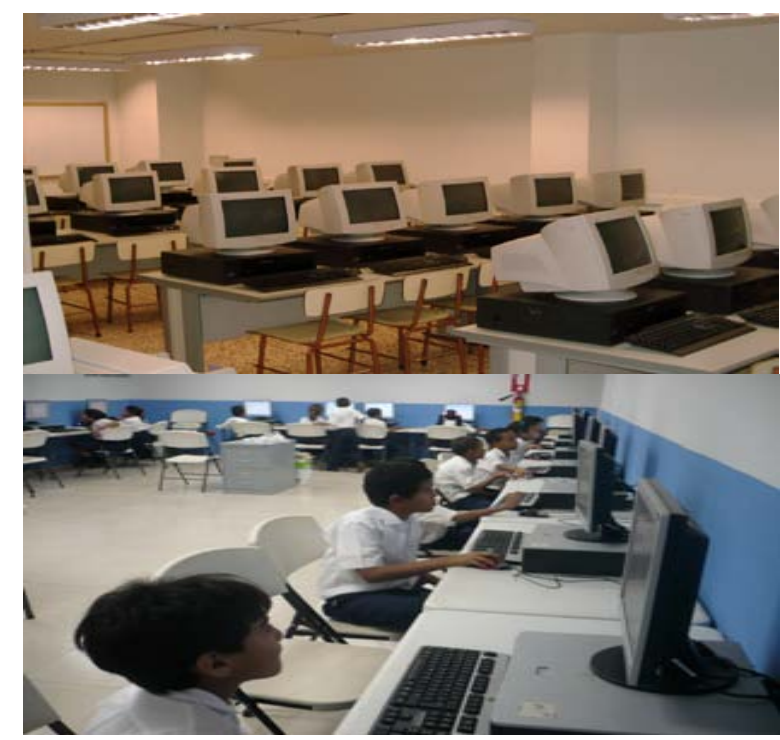

Figure 2. Comparison between a computer lab (Top) and Innovation Classroom (Bottom) 


\subsection{What is the approach of ICT in the AI?}

Accordingly to the constructivist model of Conéctate al Conocimiento (Tarte, 2006), it is necessary to have a twist in the approach of the use of technology in education. Traditionally the incursion of computers into schools, by itself, does not solve the educational problem, because introducing technologies without a pedagogical model behind will make us stay in the first wave (Scardamalia \& Bereiter 1994). In this wave the introduction of the tool becomes the objective itself. To move on to the second wave, technology has an objective, which is the use of technology regardless of the pedagogical objective, as Papert said it is a techno-centered model (Papert, 1993).

For instance, offimatics courses and seminars where the teacher learns how to use different tools (word processor, spreadsheets, etc.) without taking into consideration its pedagogical applications within the classroom, in other words, how does the teacher use it to promote learning among the students? In the third wave, technology becomes an affordance, it is used as means to achieve a goal, in the educational case, the goal is the developing of skills that allows the people to learn how to learn (Novak and Gowin 1984). Conéctate al Conocimiento aims to surf the third wave, this aim is materialized through different complementary ways, such as: Teachers' training, Support and Follow-up visits to the schools, and the supply of all the necessary technological tools needed for such a task. The teachers' training is based in theoretical fundaments from the Meaningful Learning Theory of Ausubel and the Constructivism Approach from Vigotsky theory, using tools like concept maps (Novak, 1984) powered by CmapTools (Cañas et al, 2006) as a tool for sharing and collaboration. All the tools are the means for the students could develop different collaborative projects, that are a learning strategy that integrates the approaches of collaborative learning and projects based learning, in which the students develop the necessary skills to learn how to learn.

\subsection{Who is a CAI?}

A CAI (Spanish acronym for Innovation Classroom Coordinator) is a teacher in charge of the physical space of the AI. The CAI has different roles, among them pedagogical and technological advise. The CAI does not substitute the grade teacher during the time in the AI, because the CAI works co-ordinately with the grade teacher, in this model the grade teacher provides the topics to be addressed within the AI and the CAI provides the technical know-how to better take advantage of the tools offered by the AI in order to promote meaningful learning. The CAI also complements the teachers' role as a coach for the students. The ideal CAI should fulfil a profile defined by the following aspects:

- CAI takes part in the design and implementation of Collaborative Projects within his/her school and with other schools, nationally and internationally.

- Promotes the use of all the technologies provided by the AI and search for additional technologies to make them available to teachers and students.

- Plans and takes part in the activities of the AI jointly with the grade teacher. Empowers the teacher to the point where he/she can perform with confidence in the AI without needing the CAI's support.

- The CAI's effort towards training and formation for his/her peers are extended beyond the teachers of his/her own schools (for instance: educational community, other schools, institutions, etc.)

- The CAI implements a flexible system for the use of the AI which allows for its the optimal usage (for instance: through reservations made via email, electronic agenda or other means). The use of the AI is extended beyond the normal school schedule, to include users that do not belong to the school itself.

- The CAI makes records regularly and draw conclusions from them. Besides, he/she shares the conclusion with the school teachers (for instance: the CAI organizes disclosure meetings that help in the training of the school teachers).

\section{PROMOTING THE CREATION OF A COLLABORATION NETWORK}

As we have already mentioned, each school that joins Conéctate al Conocimiento Project has its own server, where the CmapServer (Cañas et al, 2004) software is installed, this is the complementary software of the CmapTools client software and it allows the school to have a place in the Directory of Places (list of concept map servers and Internet resources) (Cañas et al, 2004) de CmapServer. Currently when the CmapTools client software is started and the user goes to "Shared Cmap in Places”, selecting “All Places” it can be observed the 
large quantity of places that starts the name “Conéctate Escuela... (Panamá)” (figure 4), which are all the places that belongs to Panamanian elementary schools where the students and teachers are saving their contents (concept maps, images, presentations, videos, etc.) with the huge possibility of sharing them with others (Figure 3). Besides all these, every resource that is stored in a CmapServer can be accessed through any Internet browser and Google indexes all the contents in the school server thus one simple search in Google of any topic from common to the elementary school curriculum (for instance: Hidroelectricas de Panamá [Hidroelectrics fo Panama]) could yield results that point to concept maps or resources from students in Panamanian elementary schools.

Currently, the IHMC team is implementing and improving an Internet concept map search engine: http://www.cmappers.net which makes it easier to look for concept maps related to a specific topic and also offers the opportunity to share them.

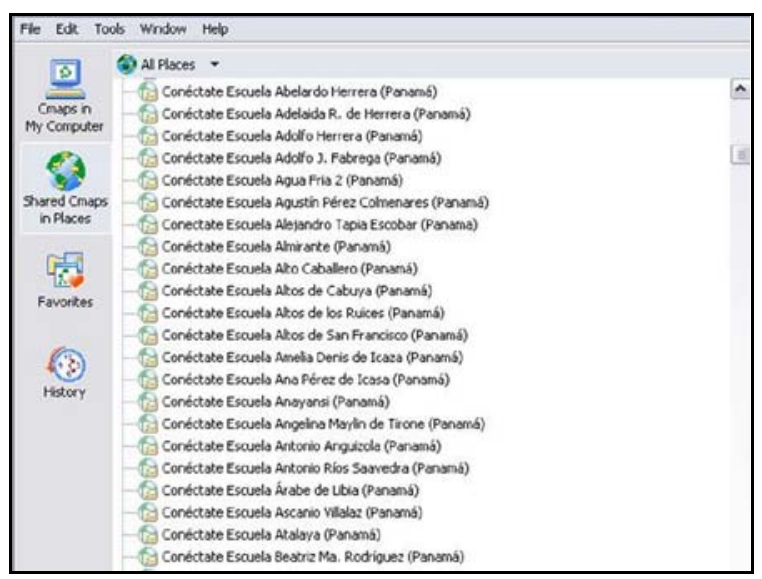

Figure 3: View of the CmapTools software that shows a little part of all the places (servers) that belong to elementary Panamanian schools.

\section{SOME SUCCESSFUL CASES}

\subsection{School network creation (Case de Bocas del Toro Province):}

Students and teachers from the Bocas del Toro province are part of a mutual support network that is growing up as we speak. Blogs, Knowledge Models (Cañas et al 2003) digital magazines are some of the contents resulting form the interaction of the network members. Project facilitators initially promoted and favored the birth of the network, however, step by step, the network took on a life of its own having students and teacher thinking and finding new manners to collaborate. Thus the network became an item to be described rather than be driven. Here are some of the spaces that teachers have created to collaborate and publish (http://reddecolaboracionbt.blogspot.com/, this is a blog that contains the links to the others schools' blogs of the network).

\subsection{Collaborate to Learn:}

The Republica de Nicaragua school, located in Colón Island, Bocas del Toro province, have carried out several collaborative activities with other educational centers in the country through the use of the tools in the AI. This has allowed the students to live experiences through collaborative projects. Among these projects there is "La Estadistica" (Statistics) (2007) where teachers and children from the Finca 41 school in Changuinola. Most recently, they participated in the "Solo Buenas Noticias" (Just Good News) (2008) with students from the El Perú elementary school in the Coclé province. Besides, the school is part of the "Bocas del Toro School Collaboration Network." Additionally, this school participates a research, jointly with other Panamanian school that takes part in Conéctate al Conocimiento project. The idea is to compare the learning that takes place when students collaborate versus those where there was no collaboration, using concept maps to watch and record the changes in the students' learning. Being collaboration one of the main strategies of Conéctate al Conocimiento, it is important that teachers and students learn to collaborate in order to take advantage of the variety of topics, contents and information that can be built and share through collaboration.

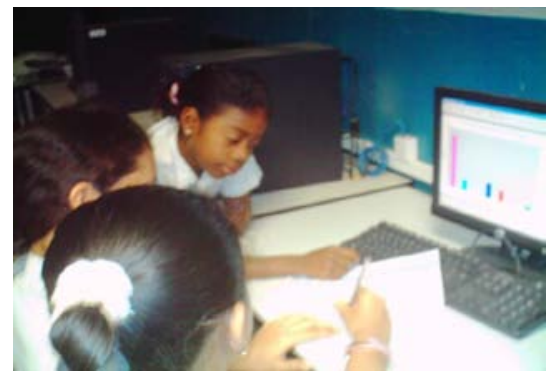

Figure 4. Sixth grade students from the República de Nicaragua school using MSOffice to create graphics in the statistics project. 


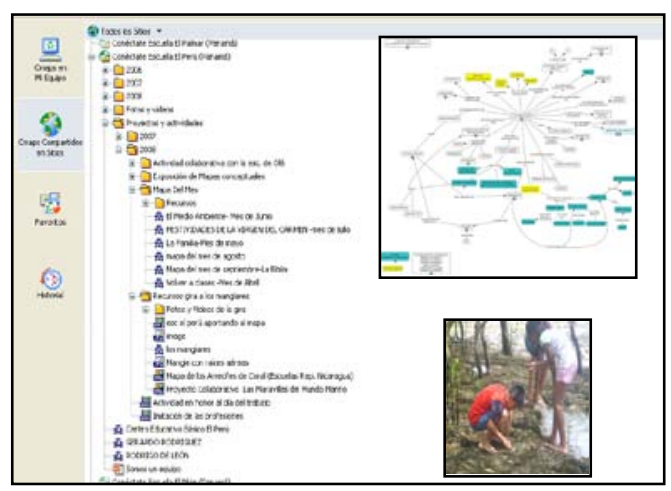

Figure 5. A screenshot of the El Peru server where all the resources made by the students are located (http://elperu.conectate.gob.pa).

\subsection{The Students are the protagonists:}

Students from the El Perú elementary school in the Coclé Province, Panamá, have developed a series of experiences through the Collaborative Projects. One of these experiences is titled "Solo Buenas Noticias" (Just Good News). This project was designed and implemented by teachers and students, with the support from Conéctate al Conocimiento facilitators. The students learned to teamwork, how to take advantage of the Internet as a space not just to look for more information regarding the topic of interests but also as a place where they can make public their knowledge about the social topic of interest in their "Map of the Month" using CmapTools. They have created videos where the students wrote the scripts (using word processing tools) as well as editing them using video editing software. The videos allowed the students to present their opinions and to contribute to the publications of topics related to the community where the school is located. The teacher Yessenia Fuentes, the school CAI, assures that the students have become more independent, the make better judgments when exchanging opinions about the topics they are addressing, the on-line interaction with students that are not physically close-by using communication tools (such as Skype or Windows Messenger) has had a positive impact, because the students worry about such things as their orthography, diction and idea coherence, additionally it helps the introvert students to be more communicative and open. All the students' productions are available in the school server via CmapTools or via web browser at http://elperu.conectate.gob.pa.

\subsection{Jaqué “A Conected Community” Technology Access in Remote Areas:}

Jaqué is a remote community in the South Pacific of Panamá, bordering with the republic of Colombia, it has an approximate population of 2,600 which 1,200 of them are Colombian displaced people, the rest are national Panamanians from several different ethnic groups such as Emberas, Wounaan and African American. Because of the remote location of this community, it lacks efficient communication means, just to public telephone that rely on satellite antenna (most of the time they are out of order and when they are in working conditions the settlers has to stand in long lines waiting to use them); one local radio station which belong to the church and the telegraph are the only means the inhabitants count with to communicate with family in the rest of the Panamanian republic, there are no signal from television channels, radio stations and of course there's no Internet access. National or international news arrive weeks later in form of newspaper clippings stapled to a bulletin board next to public telephone (Figure 6).

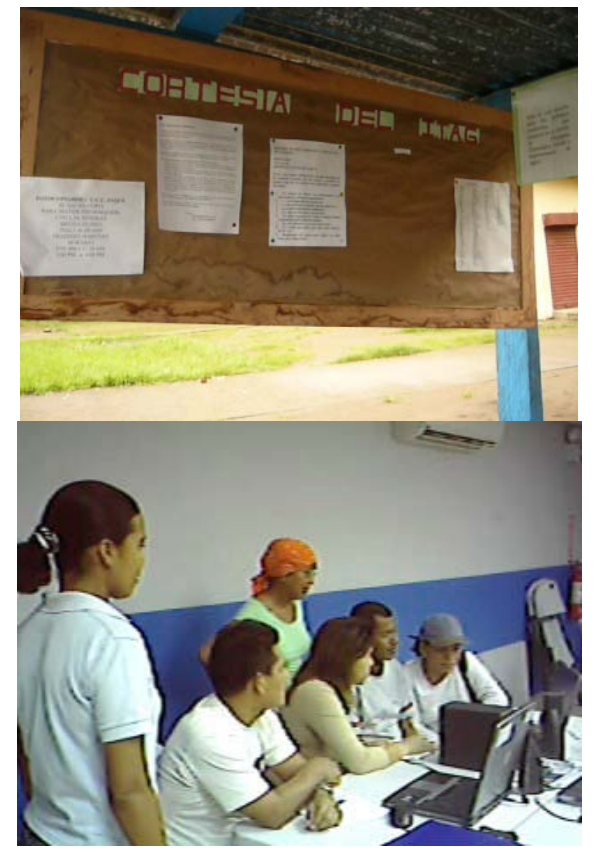

Figure 6. (Top)Bulletin board where the member of the community received the news. (Bottom)Teachers, students and members of the community taking advantage of the AI resources.

Wishing to fulfill with the goal of equity and quality in Education, Conéctate al Conocimiento, is reaching out to many remote and "disconnected" 
communities such as Jaqué, transforming the life of its inhabitants. The Marcos Medina Ambulo elementary school in Jaqué was furbished with an AI, the Conéctate al Conocimiento facilitators lived and shared with the community for three consecutive week, with the community and help the inhabitants including teachers, students, and representatives from several community sectors to use e-mail to communicate with their family in other parts of the country. This has improved the communication opportunities through the use of Internet as a mean to be informed and communicated. The teachers learned to successfully use concept map in their classes with and without the use of CmapTools. Using concept maps, teachers and community members are carrying out knowledge capture some of the processes of the activities that native group within the community carry out. For instance the Red de Mujeres de Jaqué (Jaqué's Women Network) a group of women that manufacture papers using manual processes and organic elements.

\subsection{Use of the Forums during the Encuentro de Niños Innovadores (Innovating Children Summit):}

The Encuentro de Niños Innovadores (ENI) was a great event, organized by children for children organized conceived to provide the students, it was conceived as an opportunity for the students to share their learning. The schools that organized the event were 22, and they presented 11 different projects, that is two schools worked collaboratively in one project. Comparing these numbers to the large scale in which Conéctate al Conocimiento operates they are not a significant sample of the students covered by the project. Because of the above, an on-line version of ENI was organized by Conéctate al Conocimiento, called "ENI Virtual". The objective of this version was to allow the children that could not be present physically, to access the event on-line in schools that have an AI with Internet access. The web site that was created for such task (eni.conectate.edu.pa) consisted of a Web page that described the event, a live broadcast room for each project and the Forums room. A forum room was enable for each one of the topics presented during the event, both had the same name for a easy recognition. The users could access any of the forum rooms and write their comments, there was no limit to the number of comments a user could make, or the times he/she could access a given room. Every school received a generic user to grant the students access. The students' comments are being processed and analyzed to grasp in which manner they interacted in these forums.

\section{CONCLUSION AND THE NEXT STEPS}

The implementation of ICT in Panamanian elementary schools through the use of the AI is being carried out in a fashion that has no precedent in the country. The approach that is maintained is one of taking advantage of the ICT's to build, share and publish knowledge, integrating knowledge tools such as concept maps and technological tools such as CmapTools. It can be appreciated the growth of a network of schools that increasingly need support and follow-up, at this point where connectivity in the AI takes an additional relevance because of projects that are taking shape and could be considered as our next steps:

The creation of a distance-learning platform that would allow the training of teachers, students and community members in a national scale, with an autodidact character, using a non-lineal structure and free access to the constructivism-based resources.

At this moment, Conéctate al Conocimiento is developing the website Punto de Encuentro is conceived as an on-line space in which an member of the Conéctate's community can share and create new Experiences and participates in collaborative projects. It is understood as an experience everything that is within the context of $\mathrm{CaC}$ (learning experiences, educational activities, educational events, news...). Sharing these experiences implies that the user can report his/her experiences and know other users' experiences; this is to interact with other users (There is an integration of tools to communicate the users each other like chat, e-mail.)

The user should meet, literally, with other users in the moment that he/she accesses the PE. That is why the initial interface is fundamentally a global panoramic that allows to see who is connected at that moment. The manner in which the users can be seen is through a geopolitical distribution of the educational regions. Using a map of the regions, it could be seen, in real time who is connected and where he/she is. The idea of this background is to create the visual sensation of a human network.

The experiences are reported using resources. The resources can be text, concept maps, videos, images, url addresses, file attachment, and others. The experiences as well as the resources should allow annotations (comments) from other users, in a manner that "discussions" are generated around the experiences (in resemblance to forums.) besides 
establishing a experience and resource ranking (What do you think about my experience? To be graded with stars, from 1 to 4 stars. An experience can be an isolated event, or it could be part of some project activity or a course that is being taken by the user.

This platform intends to become the online extension of Conéctate al Conocimiento, creating innovation by becoming the first platform for the integration and communication among different schools, teachers and students (lately), overcoming geographical, cultural and social barriers and allowing them to share in a common space where they can exchange experiences, contributions and knowledge.

The massive installation and use of the Nicho environment. Nicho is a software environment that provides teachers and students in a school, or group of schools, with their own unique user id, an email address, chat, and a personal space for storing documents; this same environment configures CmapTools and a CmapServer for storage of knowledge models. In Nicho, students and teachers are able to access their "space" and their communication tools from any computer in the school, and from outside the school, e.g. at home or an Internet café. Nicho was designed for Conéctate al Conocimiento, and is being deployed and used to provide a collaborative environment to public schools throughout the whole country." (Lott et al, 2008).

The implementation of a model 2 in the school (taking the AI as model 1), it is based on portable computers (laptops) instead of desktops computers. This model has already been put to practice in several schools (especially in schools that are hard to reach), however, it is still in the development stage. It will be implemented in a larger scale across the country later.

\section{REFERENCES}

Ausubel, D.P., Novak, J. D., (1978). Educational Psychology: A cognitive view. New York. Holt Rinehart \& Winston.

Cañas, A. J., Hill, G., Carff, R., Suri, N., Lott, J., Eskridge, T., et al. (2004). CmapTools: A Knowledge Modeling and Sharing Environment. In A. J. Cañas, J. D. Novak \& F. M. González (Eds.), Concept Maps: Theory, Methodology, Technology. Proceedings of the First International Conference on Concept Mapping (Vol. I, pp.125-133). Pamplona, España: Universidad Pública de Navarra.

Lipponen, L. (1999). Challenges for computer-supported collaborative learning in elementary and secondary level: Finnish perspective. In C. Hoadley (Ed.), Proceedings of CSCL '99: The Third International Conference on Computer Support for Collaborative Learning (pp. 368-375). Mahwah, NJ: Lawrence Erlbaum Associates.

Lott, J. Arroyo, M. Rodrigo, C. Pérez, C. Cañas, A. Hill, G. \& Lasso De La Vega, F. (2008). Nicho: Facilitating a Collaborative Network of Schools.

Novak, J. D., \& Cañas, A. J. (2006). The Theory Underlying Concept Maps and How to Construct Them (Technical Report No. IHMC CmapTools 2006-01). Pensacola, FL: Florida Institute for Human and Machine Cognition.

Papert, S. (1993). The children's machine: rethinking school in the age of the Computer. New York: Basic Books.

Sánches, E. Bennett, C., Vergara, C., Garrido, C. \& Cañas, A. (2008) Who Am I? Building a Sense of Pride and Belonging in a Collaborative Network. In XXXXXXXXXXXX of the Third International Conference on Concept Mapping, Tallin, Estonia, Helsinki, Finland.

Scardamalia, M., Bereiter, C. \& Lamon, M. (1994). The CSILE project: Trying to bring the classroom into World 3.

Scardamalia, M., \& Bereiter, C. (1994). Computer support for knowledge-building communities. The Journal of the Learning Sciences, 3, 265-283.

Rodríguez, M. A. \& Coloma, E. (2006). Mapas Conceptuales en las Aulas Panameñas: Aptitud para Cambiar Actitud. In A. J. Cañas, J. D. Novak (Eds.), Concept Maps: Theory, Methodology, Technology. Proceedings of the Second International Conference on Concept Mapping. San José, Costa Rica: Universidad de Costa Rica.

Rodríguez, M. A. Sánchez, E. Barrios, J. Vergara, J. Torres, O. Bravo, E. (2008). Concept Maps in Panamanian Classrooms: Searching for Photographs of Knowledge. In Concept Maps: Theory, Methodology, Technology. Proceedings of the Third International Conference on Concept Mapping, Tallin, Estonia, Helsinki, Finland.

Tarte, G. (2006). Conéctate al Conocimiento: Una Estrategia Nacional de Panamá basada en Mapas Conceptuales. In A. J. Cañas \& J. D. Novak (Eds.), Concept Maps: Theory, Methodology, Technology. Proceedings of the Second International Conference on Concept Mapping. San José, Costa Rica: Universidad de Costa Rica. 